\title{
GENOTOXICIDADE DO EXTRATO AQUOSO DE Myrsine coriacea AVALIADA POR MARCADOR ISSR
}

\author{
Marina Santos Carvalho ${ }^{1}$ \\ Thammyres de Assis Alves ${ }^{2}$ \\ Adésio Ferreira ${ }^{3}$ \\ Milene Miranda Praça-Fontes ${ }^{4}$ \\ Marcia Flores da Silva Ferreira ${ }^{5}$
}

Resumo: Myrsine coreacea tem se destacado na medicina popular por apresentar diferentes fitoquímicos em suas folhas e caules. A aplicação de compostos naturais extraídos de plantas com propriedades medicinais ou alelopáticas pode reduzir efeitos colaterais em relação à saúde humana, quando comparados com moléculas sintéticas. Mas para ser utilizado com segurança a ação dos fitoquímicos precisa ser testada. Neste trabalho objetivou-se avaliar a instabilidade genética, por meio de marcadores ISSR, induzida pelo extrato aquoso de Myrsine coriacea nos modelos Lactuca sativa e Sorghum bicolor. Utilizouse como tratamentos quatro diferentes concentrações do extrato (100\%, 50\%, 25\%, 12,5\%) e o controle negativo foi água. Verificou-se mudança nos padrões de amplificação entre os tratamentos e o controle. A concentração $100 \%$ se manteve isolado e geneticamente distante das demais nos dois bioensaios. Os resultados sugerem ação mutagênica do extrato aquoso de $M$. coreacea sob as duas espécies modelos, Lactuca sativa e Sorghum bicolor.

Palavras-chave: Alelopatia; Alface; Marcadores moleculares; Sorgo.

\footnotetext{
1 Doutoranda do Programa de Pós-Graduação em Genética e Melhoramento/Universidade Federal do Espírito Santo, Brasil. E-mail: marinasantosufes@gmail.com.

2 Mestranda do Programa de Pós-Graduação em Genética e Melhoramento/Universidade Federal do Espírito Santo. E-mail: thammyresalves@gmail.com.

3 Professor adjunto do departamento de produção vegetal/ Universidade Federal do Espírito Santo, Brasil. Email: adesioferreira@gmail.com.

4 Professora adjunta do departamento de biologia/Universidade Federal do Espírito Santo, Brasil. E-mail: milenemiranda@yahoo.com.br.

5 Professora adjunta do departamento de biologia/Universidade Federal do Espírito Santo, Brasil. E-mail: mfloressf@gmail.com.
} 